\title{
Antifungal Effect of Hubballi Propolis on Candida albicans - An In Vitro Study
}

\author{
Sowmya S ${ }^{1}$, Anil Kumar Gujjari², Raghavendra Swamy K.N. ${ }^{3}$ \\ 1, 2, 3 Department of Prosthodontics, JSS Dental College and Hospital, \\ JSS Academy of Higher Education \& Research, Mysuru, Karnataka, India.
}

\section{ABSTRACT}

\section{BACKGROUND}

As the longevity of human lives has increased, the geriatric population is increasing demonstrating more number of oral candidal infections due to decreased immunity. Natural products are being investigated to be used to treat oral candidiasis in place of synthetic drugs in selective geriatric cases. Propolis is one such natural product, which is time tested and developed by nature as an antimicrobial agent. Its toxicity is very less. It can be used in multiple forms. It has the antioxidant, anti-inflammatory properties apart from antibiotic properties and potency of the material improves as it matures with time. But the constituents of Propolis differ with the different sources of procurement. We wanted to evaluate the efficacy of the Propolis procured from Hubballi against Candida albicans in this study.

\section{METHODS}

In this invitro study, Hubballi Propolis was extracted by maceration and refluxing. Water and $70 \%$ ethanol were used as extraction solvents. Total Phenolic and flavonoid contents were determined by using Folin - Ciocalteu spectrophotometric method and Aluminium chloride colorimetric method respectively. Antimicrobial sensitivity effect of Propolis was estimated by determining the minimum inhibitory concentration (MIC) of the samples.

\section{RESULTS}

The results of the studies revealed that propolis samples have effective antifungal activity against Candida albicans with MIC range from $0.01 \mathrm{mg} / \mathrm{ml}$ to $0.03 \mathrm{mg} / \mathrm{ml}$ and comparable high total phenolic (TP) and total flavonoid (TF) contents ranging from $175.4 \pm 5.7$ to $192.2 \pm 3.3$ and $33.08 \pm 10$ to $31.73 \pm 8.5 \mathrm{mg} / \mathrm{ml}$ respectively.

\section{CONCLUSIONS}

Hubballi Propolis can be used for treating Candidal infection. Further, water extract Propolis showed better in total phenolic content (TPC) and total flavonoid content (TFC) than the alcohol extract. This finding is important to overcome the disadvantage of alcohol extract and hence very useful for application in Dentistry, cosmetics and pharmaceutical industry.

\section{KEY WORDS}

Antifungal Activity, Hubballi Propolis, Flavonoid Content, Phenolic Content
Corresponding Author: Dr. Sowmya $S$, MDS, Assistant Professor, Department of Prosthodontics JSS Dental College and Hospital, JSS Academy of Higher Education \& Research, Mysuru, Karnataka, India. E-mail: sowmya.neelan@gmail.com

DOI: $10.14260 / j e m d s / 2021 / 406$

How to Cite This Article:

Sowmya S, Gujjari AK, Swamy KNR. Antifungal effect of Hubballi Propolis on candida albicans - an in vitro study. I Evolution Med Dent Sci 2021;10(27):19791983, DOI: 10.14260/jemds/2021/406

Submission 25-02-2021, Peer Review 01-05-2021, Acceptance 07-05-2021, Published 05-07-2021.

Copyright (c) 2021 Sowmya S. et al. This is an open access article distributed under Creative Commons Attribution License [Attribution 4.0 International (CC BY 4.0)] 


\section{BACKGROUND}

Geriatric patients due to decreased immunity are more prone to oral candidiasis, which can interfere or cause systemic diseases. At times oral candidiasis becomes resistant to any type of drug or treatment modality and it may spread to the other organs and be fatal.1,2 For effective reduction of oral candidiasis (denture stomatitis) in the geriatric patients, the dental treatment protocol relies on mechanical control of Candida biofilms, depletion of predisposing factors and antifungal drug therapy. Antifungal therapy has shown good results. The available synthetic antifungal agents along with their action on candida may have unfavourable side effects. Further candida species are developing resistance to the synthetic antibiotics. ${ }^{2}$ To overcome the drawbacks of current treatment with synthetic antifungal agent, there is a shift in the research to use natural products. One such natural product or the raw material is Propolis. ${ }^{3}$ Propolis (bee glue) is a generic name. 4,5 It is non-toxic and has no-effect level (NOEL) of 1400 $\mathrm{mg} / \mathrm{kg}$ body weight / day.6,7 It is recommended not to be utilized by patients who are sensitive towards pollen and nectar. The compounds present in the propolis resin originate from a mixture of ${ }^{8}$ substances that are actively secreted by plants and are collected by bees and substances derived from bee saliva.

As the bioactive components required for propolis activity is made of components (phenolic and flavonoid) from plant and insect origin this material is least toxic and a rich source of nutrients. Hence propolis is in high demand worldwide. But its bioactive components are foraged from the vegetation by the bees, so their composition varies depending on the location and the season of collection of propolis from the hive. Hence, it is imperative that the composition of propolis obtained at different locations is verified and antifungal activity is analysed before it is used as medication in dentistry.

In this endeavour, the purpose of this study was to evaluate antifungal activity (minimum inhibitory concentration) of Hubballi Propolis. Along with antifungal activity, its total phenolic content and total flavonoid content also needs to be studied as phenolic content is considered the active component for its action. Hubballi Propolis is an unexplored propolis which is considered in this study because of the geographic features like extensive green coverage, unique and highly diverse tropical forest ecosystem in Hubballi.

\section{METHODS}

This research involved in vitro procedures to assess antifungal efficacy against Candida albicans and total phenolic and total flavonoid content of the propolis. The research protocol was approved by the Scientific Technical Committee, JSS Dental College \& Hospital, JSS AHER, and Mysore. The study was carried out for a period of one year from Dec 2019 to Nov 2020 .

\section{Materials}

Aluminum trichloride (AlCl3), Folin Ciocalteau's phenol reagent, sodium carbonate $(\mathrm{Na} 3 \mathrm{CO} 3)$, gallic acid, $\mathrm{DPPH}(3,3-$ diphenyl-1-picrylhydrazyl) and ascorbic acid. All chemical and instruments were of analytical grade and available commercially. The UV-visible spectrophotometric values were recorded in UV - 500 Spectrophotometer.

\section{Study Sample}

The selection procedure of the study samples was based on the following inclusion and exclusion criteria to procure best quality propolis.

\section{Inclusion Criteria}

1. Samples collected from spring (Mar to May) to autumn (Oct to Nov) season.

2. Sample collected from certified single apiary.

3. The sample collected by manual scraping technique only.

4. The samples collected from the wooden hive.

5. Samples should have one collection date.

\section{Exclusion Criteria}

1. The samples mixed between collection dates or hives were rejected.

2. Insufficient quantity (less than $50 \mathrm{gms}$ ) of sample was rejected as it was difficult to carry out the analysis.

Based on the inclusion and exclusion criteria the raw propolis was collected from a government certified apiary. The sample was semisolid in consistency. It was cut in to small pieces, finely grounded, divided into two equal parts, transferred to zip lock freezer bags and labelled before storage in the freezer.

\section{Extraction of Propolis}

The chemical compounds (quantitative and qualitative) of Propolis play a significant role in its antifungal activity. It is not used in the raw form, but is purified by extraction with solvents. Therefore, the extraction techniques should not harm the important compounds, especially flavonoid and phenolic. As there are no standard protocols for extraction procedure, maceration method (Figure 1), followed by refluxing was done. Literature revealed that following these methods the chemical structure of propolis is not altered and the techniques are very simple, affordable and can be used as routine extraction procedure.9-16 Commonly used solvents are water and ethanol in different percentages. Hence in this study both water extract propolis (WEP) and $70 \%$ ethanol extract propolis (AEP) were used to know the best extraction solvent for propolis.

\section{Preparation of WEP}

The Hubballi Propolis sample was dissolved in distilled water for the WEP sample of Propolis. The sample and solvent was standardised at the rate of $10 \mathrm{ml}$ water for every $1 \mathrm{gm}$ of sample. The solution was macerated (extraction of drug by allowing it to stand in contact with solvent) for $24 \mathrm{hrs}$ at room temperature. Following this the samples were refluxed (to boil the substance in such a way that the vapour formed returns to 
the stock of liquid after condensing) with water condenser for $3 \mathrm{hrs}$ at 100 degrees boiling water and then cooled at room temperature for $6 \mathrm{hrs}$. The solutions obtained were filtered through Whatmann filter paper no. 41. The filtrate was stored in a separate container and placed in the refrigerator at $4^{\circ} \mathrm{C}$. The extraction cycle was repeated twice with the residue obtained from the first filtration process. This was done to obtain all the minute trace amounts of propolis that was left over from previous cycle. Combined filtrates were concentrated and dried on boiling water bath.

From the concentrated sample (Figure 2), $1 \mathrm{mg} / \mathrm{ml}$ stock solution was prepared. This stock solution was used for analysing the total phenolic content, total flavonoid content and antifungal activity.

\section{Preparation of AEP}

The procedure for $70 \%$ ethanol extract of propolis was similar to water extract, except that $70 \%$ ethanol was used instead of distilled water as solvent.

\section{Determination of Total Phenolic Content by} Folin - Ciocalteau (FC) Colorimetric Method

The procedure used is based on the methods outlined by FolinCiocalteau. The method is based on an oxidation-reduction reaction in alkaline conditions, where the phenolate ion is oxidized while Folin's reagent is reduced, turning the solution blue. Many of the active components in propolis, such as phenolic acids and flavonoids, have a phenolic nucleus and can be evaluated by this method. ${ }^{16}$ Procedure was followed as explained in Mruthunjaya, K (2008) ${ }^{17}$ method. The content of total phenolic compounds was expressed as $\mathrm{mg} / \mathrm{g}$ gallic acid equivalent (GAE) of propolis

\section{Determination of Total Flavonoid Content by} Aluminium Chloride Colorimertic Method

The Aluminium chloride colorimetric method was modified from the procedure reported by Woisky and Salatino ${ }^{10}$ and the analysis was carried. The total flavonoid content was calculated according to the standard Quercetin calibration curve. The mean of three readings was used and expressed as mg of Quercetin equivalents (QE) / g of Propolis.

\section{Determination of Minimum Inhibitory Concentration (MIC) ${ }^{18}$}

The test determines the minimum quantity of drug required to inhibit the fungal growth. It is considered as gold standard for determining the susceptibility of organism to antimicrobial agents. Procedure -

- The brain heart infusion (BHI) broth was prepared

- (Calf brain, beef heart infusion, Proteose peptone, Dextrose, Sodium chloride and Disodium phosphate final

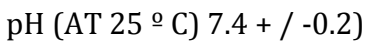

- Serial dilution of broth and stock solution was carried out. (10 sterile eppendorf tubes were taken. In the 1st tube $300 \mu \mathrm{l}$ of broth and $100 \mu \mathrm{l}$ of $2 \mathrm{mg} / \mathrm{ml}$ stock solution were added and mixed well. For the 2 nd tube $200 \mu$ l of broth and $200 \mu \mathrm{l}$ of solution from the 1st tube was transferred. For the 3rd tube $200 \mu \mathrm{l}$ of broth and $200 \mu \mathrm{l}$ of solution from the 2nd tube was transferred. This was serially repeated up to 10 th tube. $200 \mu \mathrm{l}$ was discarded from the 10th tube. This resulted in serial dilution of the concentration of the broth and stock solution.)

- All the tubes were inoculated with constant amount of test bacteria as per the groups

- The test tubes were incubated at $37^{\circ} \mathrm{C}$ for $24 \mathrm{hrs}$ in an incubator.

- $\quad$ MIC was determined by observing the turbidity after 24 hrs.

- The growth in each test tube was evaluated and recorded.

- The data was analysed by comparison with the control group

\section{Statistical Analysis}

Each procedure was carried out in triplicate. At the end of each procedure, the data were entered. Data were scrutinised and analysed using the SPSS software. Descriptive statistics, mean and standard deviations are represented in the tables.

\section{RESULTS}

\begin{tabular}{|cc|}
\hline $\begin{array}{c}\text { Total Phenolic Content } \\
192.2 \pm 0.33 \text { mg of Gallic acid equivalent } \\
\text { value per gram }\end{array}$ & $\begin{array}{c}\text { Total Flavonoid Content } \\
33.08 \pm 1 \text { mg of Quercetin equivalent } \\
\text { value per gram }\end{array}$ \\
\hline $\begin{array}{c}\text { Table 1. Total Phenolic Content and Total Flavonoid } \\
\text { Content of Propolis (WEP) from Hubballi }\end{array}$ \\
Values are expressed as Mean \pm SD for triplicate
\end{tabular}

\begin{tabular}{|ccccccccccc|}
\hline Microorganisms & \multicolumn{10}{c|}{ Concentration of Extract mg / ml } \\
Candida albicans & 0.5 & 0.25 & 0.12 & 0.06 & 0.031 & 0.01 & 0.008 & 0.004 & 0.002 & 0.001 \\
& $\mathrm{~S}$ & $\mathrm{~S}$ & $\mathrm{~S}$ & $\mathrm{~S}$ & $\mathrm{~S}$ & $\mathrm{~S}$ & $\mathrm{R}$ & $\mathrm{R}$ & $\mathrm{R}$ & $\mathrm{R}$ \\
\hline \multicolumn{8}{|c|}{ Table 2. Minimum Inhibitory Concentration (MIC) of } \\
\hline \\
\hline
\end{tabular}

Table 2 shows the sensitivity of Candida albicans to the water extract Hubballi propolis. $0.01 \mathrm{mg} / \mathrm{ml}$ of Hubballi propolis is the minimum amount required to inhibit the growth of Candida albicans.

\begin{tabular}{|c|c|}
\hline Total Phenolic Content & Total Flavonoid Content \\
\hline $\begin{array}{l}175.4 \pm 0.57 \mathrm{mg} \text { of Gallic acid } \\
\text { equivalent value per gram }\end{array}$ & $\begin{array}{c}31.73 \pm 0.85 \mathrm{mg} \text { of Quercentine equivalent value } \\
\text { per gram }\end{array}$ \\
\hline \multicolumn{2}{|c|}{$\begin{array}{l}\text { Table 3. Total Phenolic Content and Total Flavonoid } \\
\text { Content of Propolis (AEP) from Hubballi }\end{array}$} \\
\hline es are expressed Mean \pm SD & or triplicate \\
\hline
\end{tabular}

Table 3 shows the total phenolic content and total flavonoid content of $70 \%$ Ethanol extract Hubballi propolis.

\begin{tabular}{|ccccccccccc|}
\hline Microorganisms & \multicolumn{8}{c|}{ Concentration of Extract mg / ml } \\
Candida albicans & 0.5 & 0.25 & 0.12 & 0.06 & 0.031 & 0.01 & 0.008 & 0.004 & 0.002 & 0.001 \\
& $\mathrm{~S}$ & $\mathrm{~S}$ & $\mathrm{~S}$ & $\mathrm{~S}$ & $\mathrm{~S}$ & $\mathrm{R}$ & $\mathrm{R}$ & $\mathrm{R}$ & $\mathrm{R}$ & $\mathrm{R}$ \\
\hline \multicolumn{8}{|c|}{ Table 4. Minimum Inhibitory Concentration (MIC) of } \\
Propolis (AEP) from Hubballi \\
\hline
\end{tabular}

Table 4 shows the sensitivity of Candida albicans to the 70 \% Ethanol extract Hubballi propolis. $0.03 \mathrm{mg} / \mathrm{ml}$ of Hubballi propolis is the minimum amount required to inhibit the growth of Candida albicans. 


\section{DISCUSSION}

The rising candidal infection in the geriatric population because of decreased immunity and harmful side effects of synthetic antifungal therapy demands alternative safe antifungal agent. Hence the present study was undertaken to assess the efficacy of Hubballi Propolis on Candida albicans to develop novel Propolis medicament in the future to treat Candidal infection.

Hubballi is in the northern part of Karnataka with latitude $15.36^{\circ} \mathrm{N}$ and longitude $75.12^{\circ}$ E. Average maximum temperature recorded is $33^{\circ} \mathrm{C}$. The results of present study showed that Hubballi Propolis sample was highly sensitive against the tested Candida albicans, with the MIC values $0.01 \mathrm{mg} / \mathrm{ml}$ to $0.03 \mathrm{mg} / \mathrm{ml}$ (table $2 \& 4$ ) similar to Australian Propolis which had the highest activity against Candida albicans.

A Eralp akca et al. study report suggested that propolis can be used as an antifungal agent as their study showed better results with propolis than the commercially available CHX.19 Samet $\mathrm{N}$ et al. recommended commercial ethanol extracted propolis as alternative medicine for candidiasis treatment in HIV-positive patients. ${ }^{20}$ VR Santos in his chapter suggests that propolis can be used as home remedies in the treatment of denture stomatitis and oral candidiasis. ${ }^{22}$ The data of previous studies showed that when propolis was combined with other antifungal agents, there was increase in their activity against the Candida albicans. ${ }^{20-22}$ It can be suggested from the present study that the sample procured from Hubballi region will help in treating infections caused by Candida albicans.

Imaging studies with electron microscopy by Mellot et al..$^{23}$ suggested that the mechanisms of action of Brazilian green propolis on the Candida albicans was by rupturing of the cell wall of the fungus.

Further, the total phenolic content of Propolis procured from Hubballi ranged from $175.4 \pm 5.7$ to $192.2 \pm 3.3$ and the total flavonoid ranged from $33.08 \pm 10$ to $31.73 \pm 8.5 \mathrm{mg} / \mathrm{ml}$ of gallic acid equivalent (Table $1 \&$ Table 3 ). The examined Hubballi Propolis samples possessed total phenolic and total flavonoid contents which were in comparison with other parts of the world like Algeria, Brazil, China, Morocco, Poland, Korea and Turkey. ${ }^{24-32}$ The results of our studies clearly indicate that tested propolis samples procured from Hubballi with high phenolic (TP) and flavonoid (TF) contents can be selected for commercial propolis products.

The next important finding in the study was that, the water as solvent used to extract Propolis from Hubballi fared better in TPC and TFC than the alcohol as a solvent. This finding of the present study helps to overcome the drawbacks of alcohol extract which has strong residual flavour and difficulty of its usage in dentistry and pharmaceutical industry. The water extract propolis results in the study were in agreement with study by Nagai et al. The reason for water extract to excel than alcohol could be the solubility of the active components of Propolis as suggested in the previous study. ${ }^{33}$ In spite of being an invitro model, Hubballi Propolis demonstrated high antifungal activity against Candida albicans suggesting it to be an alternative for the treatment of Candidal infection.
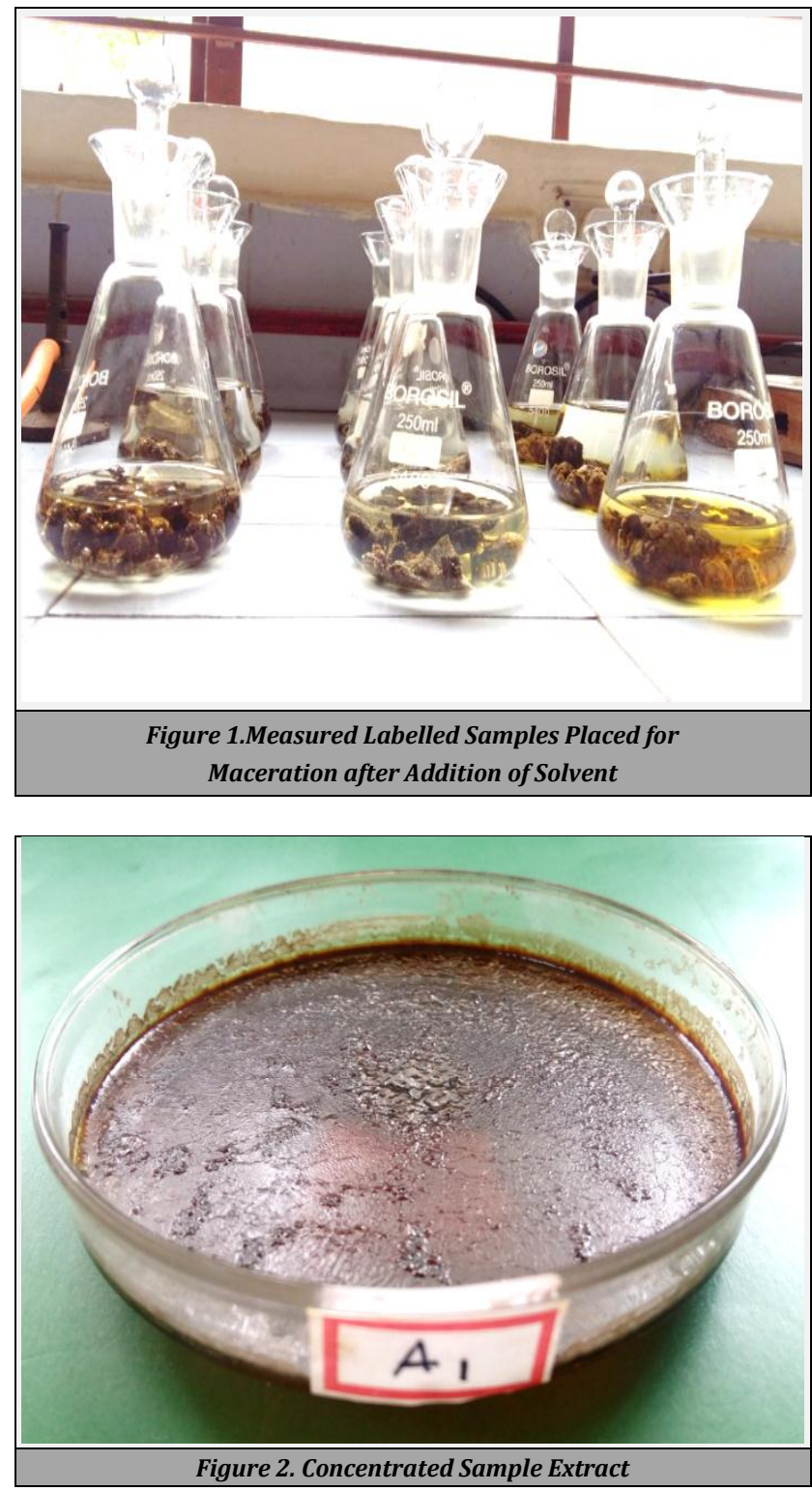

\section{CONCLUSIONS}

The promising antifungal activity of Hubballi Propolis in the present study and the literature evidence on immune modulating action of propolis with less side effects helps in considering it in treating the oral candida infection of geriatric patients. Further clinical trials are needed to establish relative efficacy of propolis and synthetic drugs.

Data sharing statement provided by the authors is available with the full text of this article at jemds.com.

Financial or other competing interests: None.

Disclosure forms provided by the authors are available with the full text of this article at jemds.com.

\section{REFERENCES}

[1] Kurek A, Grudniak AM, Kraczkiewicz-Dowjat A, et al. New antibacterial therapeutics and strategies. Pol J Microbiol 2011;60(1):3-12. 
[2] Aminov RI. A brief history of the antibiotic era: lessons learned and challenges for the future. Front Microbiol 2010;1:134.

[3] Park YK., Alencar SM, Agujar CL. Botanical origin and chemical composition of Brazilian propolis. J Agric Food Chem 2002;50(9):2502-6.

[4] Silva-Carvalho R, Baltazar F, Almeida-Aguiar C. Propolis: a complex natural product with a plethora of biological activities that can be explored for drug development. Evid Based Complement Alternat Med 2015;2015:206439.

[5] Silva BB, Rosalen PL, Cury JA, et al. Chemical composition and botanical origin of red propolis, a new type of Brazilian propolis. Evid Based Complement Alternat Med 2008;5(3):313-6.

[6] Burdock GA. Review of the biological properties and toxicity of bee propolis (propolis). Food Chem Toxicol 1998;36(4):347-63.

[7] Menniti-Ippolito F, Mazzanti G, Vitalone A, et al. Surveillance of suspected adverse reactions to natural health products: the case of propolis. Drug Saf 2008;31(5):419-23.

[8] Marcucci MC. Propolis: chemical composition, biological properties and therapeutic activity. Apidologie 1995;26(2):83-99.

[9] Woiski RG, Salatino A. Analysis of propolis: some parameters and procedures for chemical quality control. J Apicult Res 1998;37(2):99-105.

[10] Cunha IBS, Sawaya ACHF, Caetano FM, et al. Factors that influence the yield and composition of Brazilian propolis extracts. J Braz Chem Soc 2004:15(6).

[11] Trusheva B, Trunkova D, Bankova V. Different extraction methods of biologically active components from propolis: a preliminary study. Chem Cent J 2007;1:13.

[12] Machado BAS, Silva RPD, De Abreu Barreto G, et al. Chemical composition and biological activity of extracts obtained by supercritical extraction and ethanolic extraction of brown, green and red propolis derived from different geographic regions in Brazil. PLoS One 2016;11(1):e0145954.

[13] Gutierrez-Gonçalves MEJ, Marcucci MC. Antimicrobial and antioxidant activities of propolis from Ceará state. Fitos 2009;4:81-6.

[14] Margeretha I, Suniarti DF, Herda E, et al. Optimization and comparative study of different extraction methods of biologically active components of Indonesian propolis Trigona spp. Journal of Natural Products 2012;5:233-42.

[15] Pobiega K, Kras'niewska K, Derewiaka N, et al. Comparison of the antimicrobial activity of propolis extracts obtained by means of various extraction methods. J Food Sci Technol 2019;56(12):5386-95.

[16] Pujirahayu N, Ritonga H, Uslinawaty Z. Properties and flavonoids content in propolis of some extraction method of raw propolis. Int J Pharm Pharma Sci 2014;6(6):33840.
[17] Mruthunjaya K, Hukkeri VI. In vitro antioxidant and free radical scavenging potential of Parkinsonia aculeata Linn. Pharmacognosy Magazine 2008:4(13):42-51.

[18] Schwalve R, Steele-Moore L, Goodwin AC. Antimicrobial susceptibility testing protocols. $1^{\text {st }}$ edn. CRC Press 2007.

[19] Akca AE, Akca G, Topçu FT, et al. The comparative evaluation of the antimicrobial effect of propolis with chlorhexidine against oral pathogens: an in vitro study. Biomed Res Int 2016;2016:3627463.

[20] Samet N, Laurent C, Susarla SM, et al. The effect of bee propolis on recurrent aphthous stomatitis: a pilot study. Clin Oral Investig 2007;11(2):143-7.

[21] Santos VR, Pimenta FJ, Aguiar MC, et al. Oral candidiasis treatment with Brazilian ethanol propolis extract. Phytother Res 2005;19(7):652-4.

[22] Silva JC, Rodrigues S, Feás X, et al. Antimicrobial activity, phenolic profile and role in the inflammation of propolis. Food Chem Toxicol 2012;50(5):1790-5.

[23] Mello AM, Gomes RT, Lara SR, et al. The effect of Brazilian propolis on the germ tube formation and cell wall of candida. Pharmacologyonline 2006;3:352-8.

[24] Lima B, Tapia A, Luna L, et al. Main flavonoids, DPPH activity and metal content allow determination of the geographical origin of propolis from the province of San Juan (Argentina). J Agric Food Chem 2009;57(7):2691-8.

[25] Schmidt EM, Stock D, Chada FJG, et al. A comparison between characterization and biological properties of Brazilian fresh and aged propolis. Biomed Res Int 2014;2014:257617.

[26] Ahn MR, Kumazawa S, Usui Y, et al. Antioxidant activity and constituents of propolis collected in various areas of China. Food Chem 2007;101(4):1383-92.

[27] Nick K, Spyros JK, Elena T, et al. Chemical composition, antioxidant activity and antimicrobial properties of propolis extract from greece and cyprus. Food Chem 2009;116(2):452-61.

[28] Hamasaka T, Kumazawa S, Fujimoto T, et al. Antioxidant activity and constituents of propolis collected in various areas of Japan. Food Sci Technol Res 2004;10:86-92.

[29] Da Graca Miguel M, Doughmi O, Aazza S, et al. Antioxidant, anti-inflammatory and acetylcholinesterase inhibitory activities of propolis from different regions of Morocco. Food Sci Biotechnol 2014;23(1):313-22.

[30] Socha R, Gałkowska D, Bugaj $M$, et al. Phenolic composition and antioxidant activity of propolis from various regions of Poland. Nat Prod Res 2015;29(5):41622.

[31] Ahn MR, Kumazawa S, Hamasaka T, et al. Antioxidant activity and constituents of propolis collected in various areas of Korea. J Agric Food Chem 2004;52(24):7286-92.

[32] Kumazawa S, Hamasaka T, Nakayama T. Antioxidant activity of propolis of various geographic origins. Food Chemistry 2004;84(3):329-39.

[33] Nagai $T$, Inoue $R$, Inoue $H$, et al. Preparation and antioxidante properties of water extract of própolis. Food Chemistry 2003;80(1):29-33. 